\section{Animal Intelligence}

Mr. HARrison, like most of those who deal with animal communications, assumes that sounds or words must form the basis. This rests upon the assumption that speech is a primary system of communication for mankind, instead of being secondary. Many babies will begin with sign communication, and show a preference for it after they are well able to articulate words. The dog will follow human gestures as well as sounds and words. It is indeed worthy of consideration how far signs play a part in communication between animals. Instead of supposing a complicated system of words, as Mr. Harrison does, it is easy to conceive that, with the apparatus he describes, many signs may be made. Expressions of alarm, joy, direction, can be as well made with antennæe as with hands.

32, St. George's Square, October 6

HYDE CLARKE

\section{Shifting of the Earth's Axis}

PERMIT me to say that it was from the diagrams in the paper by $\mathrm{Mr}$. Christie which he quotes (NATukE, October 2, p. 536) that I drew the conclusions of decrease of latitude. In the fuller statement to which I referred, I had expressly said that it was from the Polaris observarions that a decrease of Iatitude might be deduced. The question turns on whether the truest result is obtained by trustin's entirely to Polaris, or by including other stars which are at greater N.P.D. and have more variation in the refraction : as the former is less dependent on the most uncertain element of reduction-refraction-I inclined to rely on it entirely. It would be remarkable if the great oceanic circulation should have a mean axis of motion so nearly coincident with that of the earth as not to produce $1 /$ rooth of a second change in the Pole during half a century; the presumption would seem against such a fixity.

Bromley, Kent

\section{To Find the Cube of any Number by Construction}

CAPT. H. BROCARD (of Montpellier), writing to me on the subject of my note in last week's NATURE (p. 539), communicates the following two simple constructions:-

I. On two rectangular axes $O x, O y$, take $A$ on $O x$ and $B$ on $O y$, such that $\angle O A B=\alpha$, through $B$ draw $B C \perp^{\prime \prime}$ to $A B$, meeting $O X$ in $C$, and draw $C D \perp r B C$, meeting $O Y$ in $D:$ join $A D$. Then $\tan O A D=\tan ^{3} \alpha$.

2. Take $B O D=\alpha$, from $A$ on $O D$ erect $\perp^{r}$ to meet $O B$ in $B$ : draw $B D \perp^{r}$ to $O B$, and let fall $A C \perp^{r}$ to $B . D$. Then if we take $O A^{\prime}=$ unity $\left(A^{\prime}\right.$ is the projection of $A$ on $\left.O B\right)$, $B^{\prime} C=\tan \alpha, A^{\prime} B=\tan ^{2} \alpha, C D=\tan ^{3} \alpha$.

It may be of interest to note with reference to the figure indicated in my coustruction, that $M$. Brocard finds that if $F K \perp^{r} F D$ meets $C B$ in $K$, and $K L \perp^{r} F K$ meets $F O$ $\left(\mathcal{\perp}^{r} B C\right)$ in $L$, then $L D$ passes through $H$.

October 6

R. TUCKER

\section{THE ASCENT OF WATER IN PLANTS}

THE fact that water is taken up by plants and passes off as vapour at the leaves is one of the best known data of vegetable physiology. The current of water passing up the stem of the transpiring plant is known, moreover, to be copious and rapid, and to pass through certain parts of the wood only. Apart from other questions, it has long been sought to explain by what forces this current can be maintained in the plant, and the difficulties which have arisen and been surmounted have been many; certain of these difficulties, however, are still outstanding.

It was an immense stride forwards when the fact was demonstraied that the water absorbed by the roots passes up the stem in the younger wood; and when it was recognised that in the Conifers this consists of definite elongated cells, not openly communicating, and is not complicated by the presence of vessels, \&c., the problem promised to be much simpler.

As is now well known, the earlier hypotheses which were made to explain the ascent of water in transpiration have been long put aside, as new facts were observed which could not be satisfactorily explained by them the old theory of capillarity succumbs evidently to the facts; and Quincke's hypothesis, though less easily despatched, must also be relegated to the list of past errors.

Two theories, or rather hypotheses, have attracted so much attention lately, that we may fairly regard them as the two rival views for the explanation of the ascent of the transpiration current. The one, especially advocated in its earlier shape by Boehm, seeks to explain the ascent as due essentially to the pressure of the atmosphere acting on a system of air-bubbles and water which can be shown to exist in the plant : this hypothesis, but shortly stated here, is obviously in contradiction to several important facts, e.g. the height of tall trees, and the difficulty of explaining how the atmospheric pressure could act on the closed system of the plant.

The second, and very different hypothesis, is the one recently proposed by Sachs. Assuming that the molecules of water imbibed by the wood cell-walls are held between the complex molecules of these walls in a peculiar condition-very much, in fact, as salt molecules are held between the molecules of water in the sea-then the difficulties in connection with tall trees disappear ; for by the peculiar properties of the wood cell-walls it matters not whether a given molecule of water is a yard or a hundred yards high. This hypothesis undoubtedly explains numerous facts, and, if choice lay between it and the theory of atmospheric pressure only, no doubt could exist as to which we should accept; nevertheless, there are objections to it apart from the assumption of such very peculiar properties of lignified walls.

Before saying anything as to the possible modifications of the former theory, it will be well to see how it arose in the first instance.

Jamin, in the Comptes Rendus for I860, published ar. investigation on some capillary phenomena, and particularly on the behaviour of capillary tubes containing airbubbles in addition to water.

Suppose an open capillary tube of glass filled with alternating drops of water and bubbles of air. If pressure is exerted at the one open end of such a tube, of considerable length, it is observed that the pressure is not transmitted simply through the system, but that each successive one of the alternating columns of water causes a lessening of the effect. Of course each column of water, between two air-bubbles, has two concave ends, and the changes produced in these can be observed. Without here going into the explanation of this phenomenon of the apparent disappearance of the pressure, it suffices for our purpose that an open column consisting of air-bubbles alternating with drops of water may be placed upright and the water not flow out. Jamin showed that with long tubes, the water-columns of which were sufficiently broken by air-bubbles, even a pressure of three atmospheres applied to one end filled to move the lower parts of the column. Such a column of alternating drops of water and air bubbles is called a "chapelet de Jamin."

It is known that porous bodies, such as gypsum, absorb water with great force: such bodies when saturated with water are very impervious to air, a fact which may be illustrated by means of the wet linen in any wash-tub. Jamin even proposed an explanation of the ascent of water in accordance with these facts, regarding the wood simply as a porous body.

It is not necessary to go into details as to the various modifications of the theories which in any way depended upon ordinary capillary phenomena; enough that the objection that, even if the plant had capillary tubes sufficiently fine to support the water columns required by a tall tree, the water could not flow through them so rapidly as the requirements of respiration demand seemed fatal to any of these theories, and made Sachs's assumption of the extraordinary properties of wood cell-walls appear the more necessary. Moreover, the Conifers have no such capillary tubes in the secondary wood. 
It is impossible to put in a short space all the reasons which led Sachs to draw a sharp distinction between the behaviour of water entering into preformed capillary cavities or interstices, and water which is "imbibed," i.e. forces its way between the molecules or micellæe of an organised body. It may be remarked that cases may easily be supposed where it would be difficult to draw the line, and it is certainly not easy to see why "imbibed" water should be held less fast than water in capillary interspaces. It is just here, in fact, that the assumption of the extraordinary conductibility of wood comes in.

It is clear, then, that the great difficulty which is to be put aside by assuming, with Sachs, that the water of transpiration is held in a peculiar mobile condition in the substance of the cell-walls, is that of accounting for the great height of the water columns in tall trees. The old capillary theory will not explain this away, because, although the requisite columns of water could be sup. ported, the water could not be moved as required.

Frederick Elfving brought forward an awkward objection to Sachs's theory a couple of years ago. By stopping up the lumina of the cells and vessels in such a manner that the edges of the cut elements could still be exposed, it was shown that no water could be pressed through a piece of wood. He showed, morcover, that coloured solutions passed into the cavities of the wood-cells through the thin membranes of the bordered pits, butas must be concluded from his results--not through the thick substance of the walls. Objections have been raised to some details, but it seems difficult to avoid the conclusion that Elfving's results contradict every other view than that the water passes through the thin membranes of the bordered pits, and through the cavities of the elements, and not through the main substance of the walls of the lignified cells.

Elfving has recently published a paper on this subject ("Acta Soc. Scient. Fen. nicke," t. xiv. 1884) pro posing an important modification of the views hitherto held. It is needless to go into the reasons why the theory of gaseous pressures generally must be abanconed, even in its later form, as was Boehm's air-pump theory beforc ; though it is instructive to note that much insight into the physics of the plant may be obtained by a careful study of Boehm's, and especially Hartig's, views, and the various criticisms of them. We may, however, summarise Elfving's remarks, and the chief points for criticism in all the views, as follows.

In advocating the "imbibition theory," no proof is afforded that the lumina of the elements of the living wood are ever entirely devoid of water: some water is always present at least in the cells. This does not go against either theory; but the proof that the cells were at any time entirely devoid of water would decidedly support the "imbibition theory."

Enough has already been said as to why we may reject the theory of atmospheric pressure.

Confining our attention to the wood of Conifers, for obvious reasons, the chief facts are as follows. As the young wood-cells lose their protoplasm, water, containing air in solution, occupies the cavity, and bubbles of air are formed alternating with drops of water - in fact, a series of "chapelets de Jamin" are formed; only, instead of being simple and in one long tube, each one is complex, and the broken water-columns are confined in closed chambers permeable (to water, but not to air) at the bordered pits, and therefore communicating. One advantage of this is that the "chapelets" are less easily broken.

Elfving then passes on to show that, according to Jamin's researches, these columns of water may be of any height likely to come under our consideration: we have thus no more difficulty as to the suspension of the continuous columns of water-continuous, that is, in a serpentine course. The molecules of water can pass between the supporting bubbles of air as if they had no weight, since it is only the movement of the masses of water as a whole in the longitudinal direction which is prevented by the capiliary forces in the "chapelet de Jamin"; the individual particles of water have perfect freedom of motion, and will of course travel towards the transpiration surfaces.

Elfving then goes on to show that many other facts are explained by his theory, and especially the loss of conductivity for water in branches cut off in the air. We must refer the reader to the original paper, however, for further details.

In conclusion, while there is no doubt that Sachs's ingcnious "imbibition theory" of the ascent of the water in plants was startling, on account of the bold assumption of the peculiar condition of the water in the ce!l-walls, it must not be forgotten that it was suggested after a series of profound researches into the properties of wood, and by a master-mind which had tried all previous explanations and found them wanting; moreover, the strangeness of an hypothesis is in itself no argument, and so long as the "imbibition theory" explains more facts than any other it must be accepted on those terms.

If, however, the theory proposed by Elfving turns out to cxplain the same number of facts equally well, it will have to be allowed that it rests on a foundation of a very different nature, and which can be experimentally tested. It is not easy to suggest a distinctive name for the latter theory ; perhaps it might be known as the "step" theory, since the intra-cellular movement of the water up to the leaves seems to be somewhat of the nature of a series of ascents by steps, or from side to side. We recommend the subject to the careful consideration of those physicists who have an adequate knowledge of the structure of plants.

\section{NATURAL SCIENCE IN TASMANIA}

A LTHOUGH the scientific energy of Tasmania is not $A$ all that could be wished for, still the Royal Society of Tasmania is doing something to keep the flame alive. It is much to be wished that some of its hundred Fellows would devote themselves to an investigation of the flora and fauna of their districts, about which there is still much to be learnt. The Proceedings of the Royal Society for 1882 and 1883 have just reached us. The volume for 1882 contains over I80 pages, and is illustrated by four creditably executed fithographic plates. The details of the proceedings at the monthly meetings of the Society are first given, then follow the papers, the more important of which are as follows:-On the fishes of Tasmania, with a classified catalogue of the hitherto recorded species, by Robert $\mathrm{M}$. Johnston. Incidentally he mentions that out of a population of 120,000 persons, it is estimated that about 1050 pcrsons are directly dependent upon the capture and sale of fish. Hobart is the chief centre of the industry. Out of the 188 known species, about one-third are regarded as good edible fish, though only some $2 \mathrm{I}$ of these are sufficiently abundant to be ranked as of importance from a food point of view, and of these, some, like the sprat and anchovy, are quite neglected, from want of knowledge and want of energy. Among the so-called fresh-water fish, Lates colonorum, though a well-known fish in Australian waters, is confined, so far as is yet known, in Tasmania to one small river discharging into Anson's Lagoon, on the north-east of the island. Though not a sea-going fish, it is chiefly to be found at the mouth of small streams whose connection with the sea is frequently closed by shifting sand-bars; and possibly in this way it became originally acclimatised to fresh water. The fresh-water herring (Prototroctes marcena $)$ is said to be the finest of the native fresh-water fishes; chiefly insect-feeders, they give the angler some sport. Some fourteen years ago they suddenly almost disappeared 